\title{
Refractory Nodular Sclerosis Classic Hodgkin Lymphoma
}

National Cancer Institute

\section{Source}

National Cancer Institute. Refractory Nodular Sclerosis Classic Hodgkin Lymphoma. NCI

Thesaurus. Code C8838.

Nodular sclerosis classic Hodgkin lymphoma that is resistant to treatment. 